\title{
Vacuna conjugada contra el neumococo. ¿Es una prevención universal adecuada de la enfermedad neumocócica?
}

\author{
P. Gorrotxategi Gorrotxategia ${ }^{a}$ A. Iturrioz Mata ${ }^{b}$ \\ aPediatra. CS de Ermua. Bizkaia. España. \\ bPediatra. CS de Elgóibar. Gipuzkoa. España.
}

\begin{abstract}
Resumen
Introducción: en las consultas de atención primaria debemos aconsejar a los padres sobre la posibilidad de vacunar a los niños con las vacunas antineumocócicas conjugadas, de las cuales hasta ahora sólo existía la heptavalente. En este momento se dispone de la 10-valente y la 13-valente se pondrá a la venta próximamente. El objetivo es analizar la información disponible a partir del uso de la vacuna heptavalente.

Material y métodos: tras la búsqueda bibliográfica en MEDLINE se realiza una revisión de los artículos publicados sobre la evolución de la enfermedad neumocócica tras la introducción de la vacuna antineumocócica conjugada heptavalente. Así mismo, se revisan los Boletines Epidemiológicos del Instituto de Salud Carlos III. Se analizan los datos relativos a la enfermedad neumocócica invasiva, así como los referidos a la incidencia de meningitis neumocócica y de los derrames pleurales paraneumónicos.

Conclusiones: tras el análisis realizado se plantean dudas sobre si este es el camino adecuado para combatir la enfermedad neumocócica.

Palabras clave: Streptococcus pneumoniae. Vacuna. Prevención. Bacteriemia. Meningitis. Derrame pleural.

Pneumococcal conjugate vaccine. Is it a suitable universal prevention of the pneumococcal disease?

Abstract

Introduction: in primary care consultations we have to make recommendations on conjugate vaccines. Heptavalent vaccine exists since 2000, today we have 10-valent vaccine and soon 13-valent vaccine will be available.

Method: bibliographic search in MEDLINE and revision of published papers about the evolution of the pneumococcal disease after the introduction of the pneumococcal conjugate vaccine. Also, the Spanish Epidemiologic Bulletin is revised. The analysed information refers to invasive pneumococcal disease and cases of pneumococcal meningitis and parapneumonic pleural effusions.
\end{abstract}

Pedro Gorrotxategi Gorrotxategi: pedrojesus.gorrotxategigorrotxategi@osakidetza.net

Los autores declaran no presentar conflictos de intereses en relación con la preparación y publicación de este artículo. 
Conclusions: there are doubts on the vaccine being the adequate method to combat pneumococcal disease.

Key words: Streptococcus pneumoniae. Vaccine. Prevention. Invasive pneumococcal infections. Meningitis. Pleural empyemas.

\section{Introducción}

En Atención Primaria (AP) nos encontramos ante las preguntas de los padres sobre la conveniencia o no de administrar a los niños vacunas que se encuentran fuera del calendario vacunal. Una de ellas es la vacuna conjugada frente al Streptococcus pneumoniae (neumococo), que salvo alguna comunidad concreta, como es el caso de la Comunidad de Madrid, se encuentra fuera de la financiación pública. Surge entonces la duda de qué aconsejar a estos padres. ¿Es adecuada la vacunación?, ¿qué limitaciones tiene?, ¿es una protección suficiente frente a la enfermedad neumocócica?

\section{Epidemiología del neumococo}

Las infecciones neumocócicas son una causa importante de morbilidad, hospitalización y mortalidad en todo el mundo, con 2 grupos de edad de mayor incidencia y gravedad: los niños menores de 2 años de edad y los adultos mayores de 65 años. Los pacientes con enfermedades crónicas e inmunodeficiencias (incluidas la infección por el virus de la inmunodeficiencia humana, la asplenia anatómica y la funcional) son también grupos de riesgo elevado de padecer enfermedad neumocócica invasiva. El neumococo es la bacteria que produce con más frecuencia bacteriemia oculta, neumonía, otitis media aguda, sinusitis y mastoiditis. El neumococo es el segundo agente causante, en nuestro medio, de enfermedad invasiva y meningitis bacteriana, después del meningococo. La meningitis neumocócica evoluciona con una letalidad mayor y unas complicaciones y secuelas neurológicas más frecuentes y graves que la meningocócica ${ }^{1}$.

En España, la incidencia de enfermedad neumócocica invasiva (ENI) es muy variable según las fuentes y oscila entre los 13,6 y los 107,53 casos por 100000 habitantes en niños menores de 2 años. Por el contrario, la incidencia de meningitis es homogénea, con un rango entre los 5,5 y los 15,93 casos por 100000 habitantes. Es importante reseñar que los neumococos circulantes en España presentan resistencia a los antibióticos en un elevado porcentaje'.

La existencia de 90 serotipos inmunológicamente distintos complica no- 
tablemente la realización de una vacuna para la prevención de esta enfermedad. Las vacunas antineumocócicas actuales desencadenan una respuesta inmunológica contra los polisacáridos de la cápsula. La fórmula para adultos está integrada por los polisacáridos de los 23 serotipos más prevalentes, mientras que el preparado destinado a la inmunización en lactantes y niños pequeños contiene polisacáridos y oligosacáridos de 7 serotipos unidos químicamente a proteínas transportadoras, vacuna conjugada heptavalente (con los serotipos 4, 6B, 9V, 14, 18C, $19 F$ y 23F).

\section{Vacuna conjugada heptavalente}

La vacuna conjugada heptavalente para el neumococo se introdujo en el programa de vacunación infantil de los EE.UU. en 2000 y se comercializó en España en junio de 2001. El Comité Asesor de Vacunas (CAV) de la Asociación Española de Pediatría (AEP) la incluyó en su calendario, como recomendación para todos los niños menores de 24 meses. Opcionalmente en los niños de 24 a 36 meses que acuden a guardería, los que están en condiciones sociales desfavorables, los que presentan otitis media recurrente y los que presentan especial riesgo de padecer enfermedad neumocócica.
También se incluyen los niños de 24 a 59 meses con factores de riesgo ${ }^{3}$. Dicha recomendación no se ha seguido en los calendarios vacunales de los Sistemas de Salud autonómicos (excepto en la Comunidad de Madrid), por lo que su implantación no es uniforme ni mucho menos universal. Según las estimaciones actuales, la recibe aproximadamente el 40$60 \%$ de los niños menores de 2 años. Sí está indicada en casos de niños con riesgo elevado de enfermedad neumocócica, así, según el manual de vacunaciones del Gobierno Vasco ${ }^{4}$, la vacuna neumocócica conjugada heptavalente se recomienda a: 1) niños inmunocompetentes con riesgo de enfermedad neumocócica o sus complicaciones debido a enfermedades crónicas cardiovasculares o respiratorias, diabetes mellitus o pérdida de líquido cefalorraquídeo; y a 2) niños inmunocomprometidos con asplenia anatómica o funcional, enfermedad de Hodking, leucemia, linfoma, insuficiencia renal, síndrome nefrótico, anemia de células falciformes o trasplante de órgano.

Tras los datos sobre los estudios de inmunogenicidad de la vacuna en EE.UU. ${ }^{5}$, se constató su eficacia tanto para las enfermedades invasivas $6(97,4 \%$ para los serotipos incluidos en la vacuna y $89,1 \%$ para todos los serotipos), como para las neumonías'. El CAV de la 
AEP, en un informe publicado en 2002, consideró que la vacuna ofrecía una protección casi total frente a la infección neumocócica invasiva por los serotipos que incorporaba, que eran los más frecuentes en nuestro medio y era también alta la protección que ofrecía frente a la neumonía neumocócica, incluso para las no secundarias a bacteriemia ${ }^{8}$. Dicha vacuna, según el CAV de la AEP, alcanzaba una cobertura en nuestro medio que superaba el $85 \%$ de los casos de enfermedad invasiva y se estimaba, según los estudios realizados postcomercialización, que no había aumento de las enfermedades invasivas producidas por serotipos no vacunales. Igualmente, debido a su eficacia sobre los portadores nasofaríngeos y la consiguiente disminución de contagios, se suponía que creaba una inmunidad de grupo que reforzaría el impacto de la vacunación ${ }^{9}$. Una serie de estudios posteriores parece que confirmaban esas suposiciones. La tasa de ENI en los niños estaba disminuyendo ${ }^{10}$ y en España se constató la disminución tanto de bacteriemias ${ }^{11}$ como de las meningitis neumocócicas ${ }^{12}$.

Pero algunos estudios epidemiológicos constataban las carencias de la vacuna. En un estudio retrospectivo realizado en Gipuzkoa la vacuna cubría so- lamente el $71 \%$ de las bacteriemias, el $66 \%$ de las meningitis y el $39 \%$ de las neumonías ${ }^{13}$. Posteriormente se ha constatado que, al disminuir los serotipos vacunales, está aumentando la incidencia de enfermedad por otros serotipos no incluidos en la vacuna heptavalente $^{14}$. Si en un principio parecía que la vacuna neumocócica heptavalente podría disminuir el número de $\mathrm{ENI}$, meningitis y neumonías, ahora está en duda esa afirmación.

\section{Bacteriemias por neumococo}

Según los datos del Centro Nacional de Epidemiología, que recoge semanalmente las identificaciones bacterianas declaradas al sistema de información microbiológica, por los datos que ofrece sobre bacteriemias en las que se ha aislado $S$. pneumoniae, vemos que hay un aumento progresivo de casos desde 1995 (112 casos) a 2002 (379). Con la comercialización de la vacuna en 2001 parece que hay una tendencia descendente, siendo el dato más bajo en 2004 con 292 aislamientos, pero luego vuelve a subir de manera notable, llegándose a contabilizar en 2008 hasta 765 aislamientos, más del doble de la cifra que teníamos antes de iniciar la vacunación, cuando el número de laboratorios declarantes se ha mantenido similar (figura 1$)^{15}$. 
Un estudio realizado en Euskadi' ${ }^{16}$ observa una drástica disminución de las ENI causadas por los serotipos vacunales, pero en la tasa global de ENI por cada 100000 habitantes en menores de 5 años, aunque se observa una ligera disminución, se pasa de 49,9 casos a 39,5, esta disminución no es significativa, más aún analizando la incidencia de los 2 últimos años, pues esta ha aumentado de manera considerable, pasando de una media de 30 casos en los años 2002-2005 (el dato más bajo corresponde a 2005 con 16 casos) a una tasa de 61 y 54 casos en los años 2006 y 2007. Se aprecia, por lo tanto, de forma similar a los datos aportados por el Centro Nacional de Epidemiología, un descenso transitorio tras la introducción de la vacuna con un aumento de inciden- cia de las ENI por neumococo en los últimos años.

En Barcelona, entre 1997 y 2007, se constata un aumento tanto del número total de ENI como de las debidas al serotipo 19A resistente a penicilina. Los autores dividen este espacio de tiempo en 3 periodos: prevacunal (1997-2001), postvacunal precoz (2002-2004) y postvacunal tardío (2005-2007). El número total de ENI en cada uno de los periodos es de 58,54 y 123 y el porcentaje de las causadas por el serotipo 19A pasan de 1,7\% a $14,8 \%$ y $21,9 \%^{17}$. En los 2 primeros periodos las cepas de serotipo 19A eran sensibles a la penicilina, mientras que en el periodo postvacunal tardío 12 de los 27 casos eran resistentes a la penicilina. Esta evolución de la ENI la podemos ver de forma gráfica en la figura 2.

Figura 1. Bacteriemias por neumococo notificadas al Sistema de Información Microbiológica. 1995-20085.

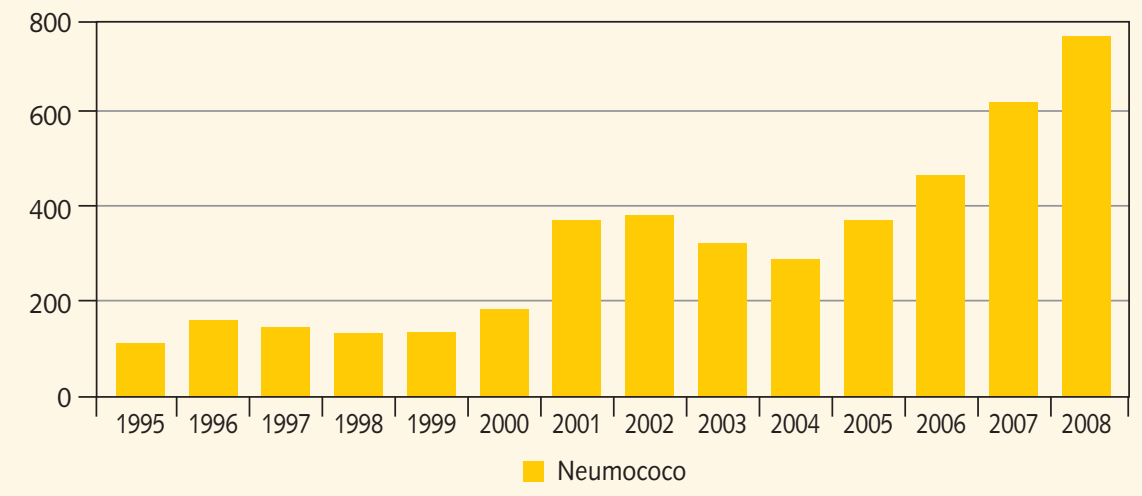


La causa del incremento de las ENI puede ser tanto el aumento de su incidencia como la mayor vigilancia epidemiológica. En un estudio realizado en Bélgica se constató que el seguimiento exhaustivo de la infección neumocócica hace que aumente el registro de su incidencia ${ }^{18}$. Igualmente, los pediatras de urgencias valoran positivamente la vacunación antineumocócica. En una encuesta realizada en servicios de urgencias hospitalarios sobre el manejo que harían de 2 casos clínicos hipotéticos de fiebre sin foco, según las respuestas obtenidas, el estado vacunal frente al neumococo influiría en la toma de decisiones. Si los resultados de esta encuesta reflejaran la práctica clínica real, la vacunación produciría un descenso del número de pruebas diagnósticas ${ }^{19}$.

\section{Meningitis neumocócica}

La segunda patología que la vacuna pretendía evitar era la meningitis neumocócica. En un estudio realizado en Francia, cuyas tasas de vacunación son similares a las nuestras, y que recoge los datos sobre la meningitis neumocócica entre 2001 y 2007, no se observa el "teóricamente" previsible descenso de las meningitis neumocócicas ${ }^{20}$. El número total de meningitis no ha disminuido (127 en 2001 y 121 en 2007) y los serotipos inicialmente eran cubiertos mayoritariamente por la vacuna heptavalente $(63,9 \%$ en 2001 mientras que en 2007 solo cubría el

Figura 2. Emergencia de enfermedad neumocócica invasiva causada por un serotipo 19A en Barcelona ${ }^{17}$. Incidencia de casos del serotipo 19A con respecto del total de casos de enfermedad neumocócica invasiva.

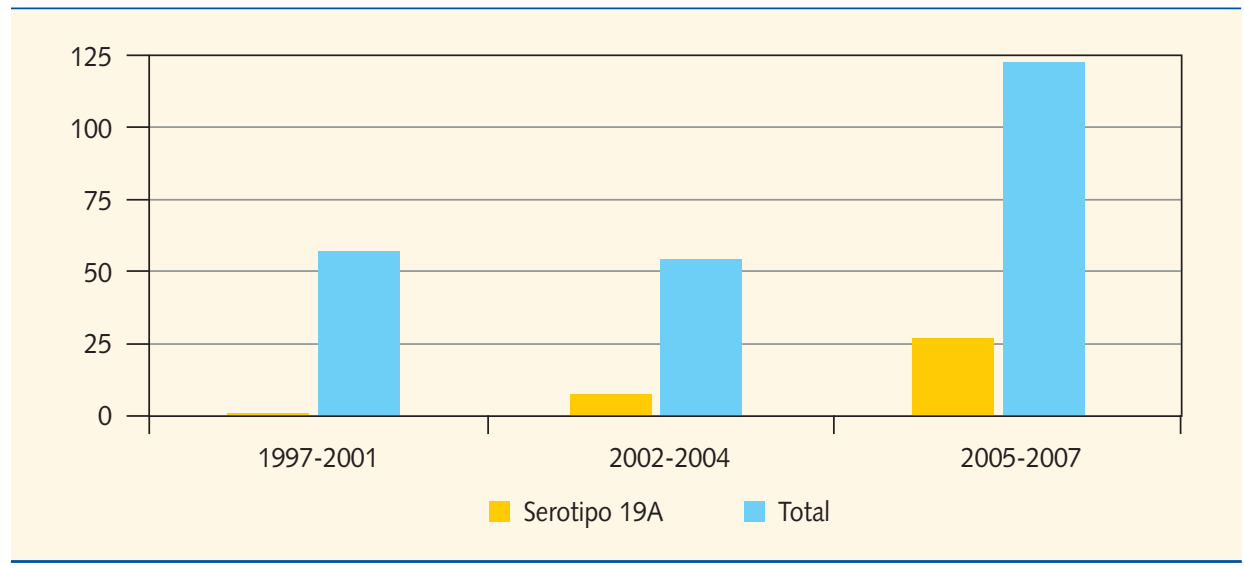


$22,8 \%)$. En el momento actual, 2007, el porcentaje de serotipos que cubriría la vacuna 13 -valente no llegaría al $60 \%$ (figura 3).

\section{Derrames pleurales}

Otro dato preocupante, tras la introducción de la vacuna heptavalente, es el aumento de los empiemas paraneumóni-

Figura 3. Meningitis neumocócicas en Francia de 2001 a 2007. Revisión de $832 \operatorname{casos}^{19}$.

3A. Número de casos en vacunados y no vacunados (vacuna heptavalente).

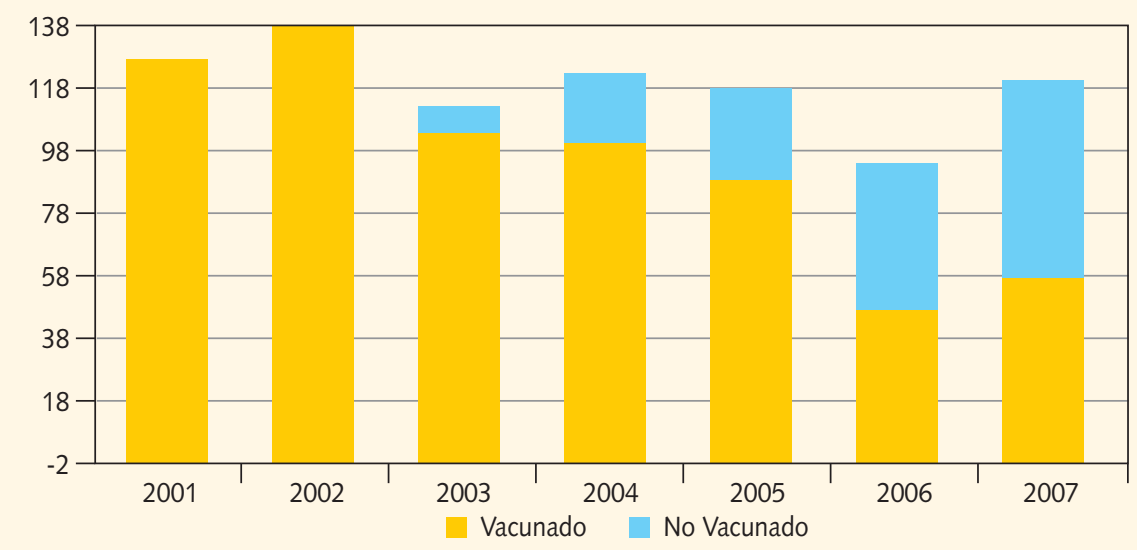

3B. Porcentaje de cobertura de los serotipos encontrados con la vacuna 7-valente, 10-valente, 13-valente y serotipos no incluidos en ninguna de ellas.

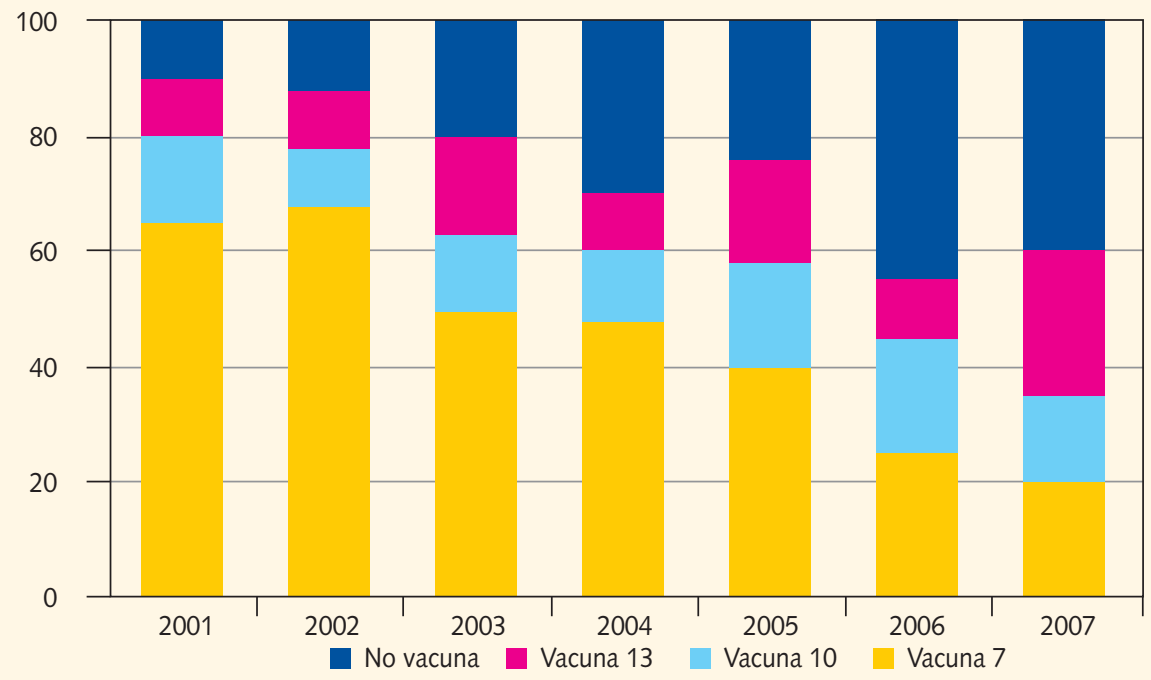


cos. Diversos estudios han puesto de manifiesto que el aumento de los serotipos 1, 3 y 19A, no incluidos en la vacuna, serían responsables de dicho aumento ${ }^{21-22}$. El serotipo 1 es el más involucrado en el desarrollo de los derrames pleurales suponiendo en un estudio el $48 \%$ de los casos $^{23}$. Según los datos de la región norteamericana de Intermountain West, el número de casos de empiema pleural pasó de 38 casos/año a 71,5 casos/año $0^{21-24}$. En un estudio realizado en España ${ }^{25}$ los autores atribuyen el aumento de derrames al aumento global del número de neumonías bacterianas, manteniéndose constante la proporción de complicaciones (aunque repasando los datos del estudio donde se afirma esto, el número de neumonías aumenta ligeramente, de 36 a 41 , mientras que el porcentaje de derrames pasa de $16 \%$ a $24 \%$ como puede verse en la tabla 1).

El aumento de los casos de neumonía se ha encontrado también en otros estu- dios. En un análisis retrospectivo de la Unidad de Enfermedades Infecciosas del Hospital La Paz entre enero de 2001 y diciembre de 2004, observan un aumento de los casos de neumonía bacteriana adquirida en la comunidad de posible origen neumocócico ${ }^{26}$. Añadiendo los casos de un estudio anterior ${ }^{27}$ y viendo la evolución entre 1988 y 2004, observan que la incidencia de neumonía por cada 1000 niños menores de 14 años pasa de 0,99 a 1,72 y de cada 100 ingresos en 1998 había 6,91 casos de neumonía, mientras que en 2004 el número de casos de neumonía era 14,4, lo que indica que la incidencia se ha incrementado al doble en los últimos 7 años.

Desde un editorial de la revista Anales de Pediatría ${ }^{28}$ y desde los documentos publicados por el CAV de la AEP $^{29}$ se afirma que la causa de este incremento es desconocida, y hasta la fecha no existen datos que permitan vincularlo a la vacuna antineumocócica conjugada

Tabla 1. Incidencia de neumonías y derrames pleurales, y su porcentaje desde el año 1999 a 2005

\begin{tabular}{l|l|l|l}
\hline Año & Neumonias & Derrames & $\%$ \\
\hline 2000 & 36 & 6 & 16 \\
\hline 2001 & 31 & 5 & 16 \\
\hline 2002 & 23 & 3 & 13 \\
2003 & 22 & 2 & 9 \\
2004 & 43 & 8 & 18 \\
\hline 2005 & 41 & 10 & 24 \\
\hline
\end{tabular}

Fuente: Obando I, Muñoz-Almagro C, Arroyo LA. Pediatric paraneumonic empyema, Spain. Emerg Infect Dis. 2008;14:1390-7. 
heptavalente. Igualmente, hay constancia de que desde finales de los años 90 , por lo tanto antes de la implantación de la vacuna, ya se observó un aumento significativo de los serotipos 1, 5, 6A, $7 F$ y $19 A^{30}$.

\section{Situación actual}

El estudio Heracles, estudio prospectivo a 3 años, multicéntrico (con la participación de 20 hospitales de la Comunidad de Madrid públicos y privados), en el que se incluyen todos los niños menores de 15 años con ENI que requieren ingreso hospitalario, ha realizado un primer análisis intermedio al año de su inicio. Según este análisis intermedio ${ }^{31}$, los serotipos 1 y 5 son los más frecuentes (22,1 y $21,5 \%$, respectivamente, seguidos del 19A (14,1\%), que ha incrementado notablemente su presencia, y el $7 \mathrm{~F}$ $(9,2 \%)$ y el $6 \mathrm{~A}$. En cuanto a la patología predominante, el serotipo 1 se asocia a derrame pleural y neumonía, mientras que el $19 \mathrm{~A}$ y el $6 \mathrm{~A}$ a meningitis.

En Estados Unidos, lugar donde se inició la vacunación neumocócica heptavalente, se produjo en los años siguientes un gran aumento del serotipo 19A (300\% en menores de 5 años) ${ }^{32}$. Este serotipo $19 \mathrm{~A}$, según los datos del laboratorio de referencia de $S$. pneumoniae, en el primer semestre de 2008 es el principal productor de ENI y ha aumentado especialmente en el grupo de 0-14 años de edad en los últimos 10 años. También han aumentado en los últimos 10 años los serotipos 1, 5 y 7F, considerados altamente invasivos ${ }^{33}$, aunque como ya hemos citado anteriormente, ese aumento, en España, se inició antes de la implantación de la vacuna heptavalente ${ }^{30}$.

En un estudio realizado en Alemania en el que quisieron relacionar el serotipo con el riesgo de gravedad o evolución fatal, constataron que el más letal de los serotipos era el 7F (responsable del $14,8 \%$ de las muertes) seguido del $23 \mathrm{~F}(8,3 \%)$ y $3(8,3 \%)$, en cuanto a la producción de secuelas graves también el $7 F$ fue el predominante $(40,7 \%)^{34}$.

\section{Nuevas vacunas conjugadas 10 y 13-valente}

La vacuna heptavalente, por lo tanto, no ha tenido la eficacia que se esperaba en España. Una razón que en parte puede explicar este resultado es que en España la tasa de vacunación ha sido del $50 \%$ y que los serotipos incluidos en la vacuna heptavalente sólo cubrían el $60 \%$ de las $\mathrm{ENI}$, ya que en los países en los que la vacunación ha sido universal han disminuido las ENI con un cierto reemplazo de serotipos no vacunales pero sin alcanzar las cifras de ENI previas ${ }^{35-36}$. Esta misma con- 
clusión se expresaba en un trabajo de revisión publicado en la Revista Pediatría de Atención Primaria, titulado "Luces y sombras, sobre la vacuna conjugada heptavalente" ${ }^{37}$, que afirmaba que la vacuna conjugada heptavalente ha permitido reducir la enfermedad neumocócica, a la vez que aconsejaba continuar con la recomendación de vacunar. Igualmente, según esos autores, se debe realizar una vigilancia epidemiológica con el fin de tipificar los neumococos más frecuentes para introducir vacunas con mayor amplitud de serotipos.

En una campaña vacunal es de esperar que la carga global de la enfermedad disminuya y que, aunque se observen más casos de serotipos no vacunales, el conjunto de la enfermedad en cuestión sea menor. Eso es, por ejemplo, lo que ha sucedido con la vacunación contra el Haemophilus influenzae tipo b (HIB). La introducción de la vacuna conjugada conllevó una mayor proporción de casos atribuibles a cepas no tipables, por la reducción de la enfermedad del HIB, pero, al contrario de lo que ha sucedido con el programa de vacunación conjugada frente al neumococo, no hay evidencia que sugiera que la vacunación en masa contra el HIB en la infancia conlleve un reemplazamiento de serotipos ni en los portadores ni en la enfermedad ${ }^{38}$.
Por todo ello, tras el "escaso éxito" de la vacuna heptavalente la industria farmacéutica ha preparado nuevas vacunas con más serotipos. Ahora se ha comenzado a distribuir una vacuna con 10 serotipos $^{39}$ y se anuncia para un futuro próximo una vacuna con 13.

Además de los serotipos presentes en la heptavalente, la vacuna 10-valente cubre los serotipos 1, 5 y $7 \mathrm{~F}$ y la 13-valente, además de los citados 3,6A y 19A. Los 3 primeros son los que han sido responsables del aumento de los derrames pleurales, neumonías y de evolución fatal de algunos de los casos, el 19A que incorpora la 13-valente se ha visto que ha aumentado considerablemente en las bacteriemias en los últimos años.

Muchos autores se muestran esperanzados con estas nuevas vacunas conjugadas. Pero, ¿es esta la solución?, ¿las vacunas 10 -valente y 13 -valente evitarán que otros serotipos ocupen el lugar de los serotipos vacunales?, ¿estarán los niños más protegidos, en términos de salud publica, con la implantación de las nuevas vacunas?

En la progresiva medicalización de la vida cotidiana, los aspectos preventivos de la enfermedad también pueden verse afectados. En ocasiones, se ponen en marcha programas preventivos sin una 
suficiente evidencia científica o se instauran actividades sin suficientes datos de eficacia o seguridad, tal como se apunta en una de las últimas publicaciones de nuestra revista ${ }^{40}$ : ¿ puede ser la prevención de la enfermedad neumocócica una de ellas?

A nosotros, como pediatras de AP, nos preocupa tanto la protección individual de un niño frente a diversos serotipos de neumococo, aspecto que logran las vacunas conjugadas, como la situación sanitaria del neumococo en su conjunto, aspecto este último sobre el que la vacuna conjugada no ha demostrado suficientemente su efectividad. Muchas preguntas siguen sin respuesta, por lo que tenemos que matizar mucho la información que ofrecemos a los padres sobre estas vacunas para que sea veraz y no induzca a engaño en los mismos.

\section{Bibliografía}

1. Moraga Llop F. Espectro clínico de la infección neumocócica. An Pediatr (Barc). 2002;56 (Supl 1):31-9.

2. Delgado Rubio A, Martinón Torres F. Enfermedad neumocócica. En: Comité Asesor en Vacunas, AEP. Manual de vacunas en Pediatría 2008. Madrid: AEP; 2008. p. 392-406.

3. Comité Asesor en Vacunas, AEP. La enfermedad neumocócica y su prevención. Vacuna neumocócica conjugada heptavalente. An Esp Pediatr. 2002;56:79-90.

4. Manual de vacunaciones. Vitoria: Servicio Central de Publicaciones, Gobierno Vasco; 2001.

5. Black S, Shinefield H, Fireman B. Efficacy, safety and inmunogenicity of Heptavalent Pneumococcal Conjugate Vaccine in children. Pediatr Infect Dis J. 2000;19:187-95.

6. Black S, Shinefield $H$, Hansen J. Postlicensure evaluation of the effectiveness of seven valent pneumococcal conjugate vaccine. Pediatr Infect Dis J. 2001;20:1105-7.
7. Black S, Shinefield $H$, Hansen J. Effectiveness of heptavalent pneumococcal conjugate vaccine in children younger than five years of age for prevention of pneumonia. Pediatr Infect Dis J. 2002;21:810-5.

8. Blanco Quirós A, Jiménez Sánchez F, Asensi Botet $F$, Bernaola Iturbe $E$, de Juan Martín F, García Pérez J, y cols. Incidencia de la infección neumocócica invasora en niños menores de dos años. Vacuna neumocócica heptavalente. Situación en España. An Pediatr (Barc). 2002;57: 287-9.

9. De Juan Martín F. Impacto de la inmunización frente a las enfermedades invasoras por neumococo: vacuna neumocócica conjugada. An Pediatr (Barc). 2002;57 (Supl 1):24-30.

10. Poehling KA, Talbot TR, Griffin Mr. Invasive pneumococcal disease among infants before and after introduction of pneumococcal conjugate vaccine. JAMA. 2006;295:1668-74.

11. Benito Fernández J, Raso SM, Rocheville Gurutzeta I, Sánchez Etxaniz J, Azcunaga Santibáñez B, Capapé Zache S. Pneumococcal bacte- 
raemia among infants with fever without known source before and after introduction pneumococcal conjugate vaccine in the Basque Country of Spain. Pediatr Infect Dis J. 2007;26:667-71.

12. Casado Flores J, Rodrigo C, Aristegui J, Martinón JM, Fenoll A, Méndez C. Decline in pneumococcal meningitis in Spain after introduction of the heptavalent pneumococcal conjugate vaccine. Pediatr Infect Dis J. 2008;27:1020-2.

13. Iglesias Sánchez L, Pérez-Yarza EG, García-Arenzana JM, Valiente Méndez A, PérezTrallero E. Epidemiología de la enfermedad invasiva neumocócica en Guipúzcoa (1981-2001). An Pediatr (Barc). 2002:57:401-7.

14. Muñoz Almagro $C$, Jordán I, Gene A, Latorre C, García García JJ, Pallares R. Emergence of invasive pneumococcal disease caused by nonvaccine serotypes in the era of 7 valent conjugate vaccine. Clin Infect Dis. 2008;46:174-82.

15. Resultados de la declaración al Sistema de Información Microbiológica. Bol Epidemiol Sem. 2008;16:270-1; 2007;15:270-1; 2006;14:260-3; 2005;13:271-2; 2004;12:294-5; 2003;11:331-4; 2002;10:282-3; 2000;8:272-5; 1999;7:240-3; 1998;6:306-7; 1997;5:320-2; 1996;4:401-3.

16. Pérez-Trallero E, Marimón JM, Ercibengoa $M$, Vicente $D$, Pérez-Yarza EG. Invasive Streptococcus pneumoniae infections in children and older adults in the north of Spain before and after the introduction of the heptavalent pneumococcal conjugate vaccine. Eur J Clin Microbiol Infect Dis. 2009;28:731-8.

17. Muñoz Almagro $C$, Esteva $C$, Fernández de Sevilla M, Selva L, Gene A, Pallares R. Emergence of invasive pneumococcal disease caused by multidrug resistant serotype $19 \mathrm{~A}$ among children in Barcelona. J Infect. 2009;59:75-82.

18. Vergison A, Tuerlinckx D, Verhaegen J, Malfroot A; Belgian Invasive Pneumococcal Disease Study Group. Epidemiologic features of in- vasive pneumococcal disease in Belgian children: passive surveillance is not enough. Pediatrics. 2006;118:e801-9.

19. Capapé Zache S, Luaces Cubells C, Garrido Romero R, Claret Teruel G, Fernández Landaluce A, Benito Fernández J. Impacto de la vacunación neumocócica en el manejo del lactante con fiebre, en relación al porcentaje de vacunación. An Pediatr (Barc). 2007;67:30-6.

20. Levy $C$, Varon $E$, Binguen E. Méningites à pneumocoque de l'enfant en France: 832 cas de 2001 à 2007. Arch Pediatr. 2008;15:S111-8.

21. Ochoa Sangrador C, Castro Rodríguez JA. Los empiemas paraneumónicos han aumentado tras la introducción de la vacuna neumocócica conjugada heptavalente. Evid Pediatr. 2006;2:31.

22. Obando Santaella I, Sánchez Tatay D, Mateos Wichmann I, Torronteras Santiago R, León Leal JA. Incremento en la incidencia de los derrames pleurales paraneumónicos. An Pediatr (Barc). 2006;64:176-7.

23. Obando I, Muñoz-Almagro C, Arroyo LA. Pediatric paraneumonic empyema, Spain. Emerg Infect Dis. 2008;14:1390-7.

24. Byington $\mathrm{CL}$, Korgenski K, Daly J. Impact of the pneumococcal conjugate vaccine in pneumococcal parapneumonic empyema. Pediatr Infect Dis J. 2006;25:250-4.

25. Bueno Campaña $M$, Agúndez Reigosa $B$, Jimeno Ruiz S, Echávarri Olavarría F, Martínez Granero MA. ¿Está aumentando la incidencia de derrames pleurales paraneumónicos? An Pediatr (Barc). 2008;68:92-8.

26. Del Castillo Martín F, Lodoso Torrecilla B, Baquero Artigao F, García Miguel MJ, de José Gómez MI, Aracil Santos J, y cols. Incremento de la incidencia de neumonía bacteriana entre 2001 y 2004. An Pediatr (Barc). 2008:68:99-102.

27. Del Castillo Martín F, Hernández González $\mathrm{N}$, Montero Reguera R, Baquero Artigao F, Bor- 
que Andrés C, García Miguel MJ, y cols. Aumento de incidencia de neumonías de posible origen bacteriano en el último trienio. Acta Pediatr Esp. 2004;62:54-9.

28. García-Algara O, Martínez-Roig A. ¿Aumenta el empiema neumónico? An Pediatr (Barc). 2008:68:89-91.

29. Martinón Torres F, Bernaola Iturbe E, Giménez Sánchez F (Comité Asesor de Vacunas). ¿Por qué hay más empiemas pediátricos en España? An Pediatr (Barc). 2008:68:158-9.

30. Fenoll A, Granizo JJ, Aguilar L, Giménez MJ, Aragoneses-Fenoll L, Hanquet $G$ et al. Temporal trends of invasive Streptococcus pneumoniae serotypes and antimicrobial resistance patterns in Spain from 1979 to 2007. J Clin Microbiol. 2009: 47:1012-20.

31. Picazo JJ. Siete años de experiencia con la vacuna PCV7 en España. La vigilancia epidemiológica de las enfermedades infecciosas: un desafío técnico y una responsabilidad compartida. Actas del II Encuentro de Enfermedades Infecciosas; 2 y 3 de octubre de 2008; Salamanca: Junta de Castilla y León; 2008. p. 39-42.

32. Van Beneden C. La importancia de los sistemas de vigilancia: evaluación del impacto de la vacunación de PCV7 en EE.UU. La vigilancia epidemiológica de las enfermedades infecciosas: un desafío técnico y una responsabilidad compartida. Actas del II Encuentro de Enfermedades Infecciosas; 2 y 3 de octubre de 2008; Salamanca: Junta de Castilla y León; 2008. p. 27-30.

33. Fenoll A. Papel del laboratorio de referencia en la vigilancia epidemiológica de la ENI: evolución de los serotipos neumocócicos a lo largo de casi tres décadas. La vigilancia epidemiológica de las enfermedades infecciosas: un desafío técnico y una responsabilidad compartida. Actas del II Encuentro de Enfermedades Infecciosas; 2 y 3 de octubre de 2008; Salamanca: Junta de Castilla y León; 2008. p. 35-8.

34. Rückinger $S$, Kries $R$, Siedler $A$, Linden $M$. Association of serotype of Streptococcus pneumoniae with risk of severe and fatal outcome. Pediatr Infect Dis J. 2009;28:118-22.

35. García García JJ. La enfermedad neumocócica en nuestro medio. Implicaciones para el pediatra de Urgencias. Urgencias Pediatr. 2009;6(2):4-7.

36. Ruiz-Canela Cáceres J, Juanes de Toledo B. Enfermedad neumocócica invasiva: aumento de la incidencia de serotipos no vacunales tras la vacunación universal de los niños nativos de Alaska. Evid Pediatr. 2007:3:74.

37. San José González MÁ, Méndez Fernández P. Vacuna conjugada neumocócica heptavalente: ¿luces y sombras? Rev Pediatr Aten Primaria. 2008;10:467-88.

38. Prado MJ, Sobrino L, García M, Velasco L, Solor P. Enfermedad invasiva por Haemophilus influenzae en España- Sistema de Información Microbiológica. Años 1993-2008. Bol Epidemiol Sem. 2009;17:73-6.

39. Wysocki J, Galaj A, Omeñaca F. Immunogenicity of the new 10-valent pneumoccoal non-typeable Haemophilus influenzae protein D conjugate (PHiD-CV) in infants after 3-dose priming before 6 months of age. Proceedings $6^{\text {th }}$ Internatnional Symposium on Pneumococci \& Pneumococcal Diseases. June 8-12, 2008. Reykjavik, Iceland; 2008.

40. Morell Sixto ME, Martínez González C, Quintana Gómez JL. Disease mongering, el lucrativo negocio de la promoción de enfermedades. Rev Pediatr Aten Primaria. 2009;11:491-512. 